Chirurgia (2017) 112: $546-557$

No. 5, September - October

Copyright@ Celsius

http://dx.doi.org/10.21614/chirurgia.112.5.546

\title{
Enhanced Recovery After Surgery (ERAS) - The Evidence in Geriatric Emergency Surgery: A Systematic Review
}

\author{
Mihai Paduraru', Luca Ponchietti', Isidro Martinez Casas ${ }^{2}$, Peter Svenningsen ${ }^{3}$, Jorge Pereira ${ }^{4}$, \\ Aitor Landaluce-Olavarria ${ }^{5}$, Roser Farre Font ${ }^{6}$, Iciar Pascual Miguel ${ }^{7}$, Bakarne Ugarte-Sierra ${ }^{5}$
}

'Department of Emergency Surgery, Milton Keynes University Hospital, United Kingdom

${ }^{2}$ Department of Emergency Surgery, Jaen Hospital Complex, Spain

${ }^{3}$ Department of General Surgery, Rigshospitalet Hospital, Region Hovedstaden, Danmark

${ }^{4}$ Department of General Surgery, Hospital de Săo Teotónio, Portugal

${ }^{5}$ Department of General Surgery, Galdakao-Usansolo Hospital, Spain

${ }^{6}$ Department of General Surgery, Althaia, Manresa Hospital, Spain

'Department of General Surgery, Germans Trias i Pujol University Hospital, Spain

Corresponding author:

Mihai Paduraru, PhD, MSc, MD

Consultant General Surgeon

Emergency Surgery

Milton Keynes University Hospital

NHS Foundation Trust, UK

Standing Way, Eaglestone, MK6 5LD

E-mail: paduraru_mihai@yahoo.com

\section{Abbreviations:}

ES - Emergency surgery,

ERAS - Enhanced recovery after surgery,

GES - Geriatric emergency surgery,

LOS - Length of stay,

CC - Conventional care,

PD - Pancreaticoduodenectomy

Received: 01.12.2016

Accepted: 05.01.2017

\section{Rezumat}

Recuperarea postoperatorie accelerată - evidența stiințifică actuală în chirurgia geriatrică de urgență: revizie sistematică

Chirurgia geriatrică, într-un proces de prevalență accelerantă în practica clinică, generează un înalt interes cu privire la rezultatele postoperatorii în cazurile de urgență. Gestiunea resurselos existente pentru îmbunatătirea parametrilor postoperați în acest grup de pacienți, reprezintă un important subiect de dezbatere.

Obiective: Determinarea fezabilității şi securității aplicării protocoalelor ERAS (Enhanced recovery after surgery) în chirurgia geriatrice de urgență.

Material şi metodă: Două căutări bibliografice au fost realizate în relație cu ERAS, vârstnici şi chirurgie de urgență, cu scopul de a identifica evidența stiițifică specifică. Parametrii studiați au fost: complicațiile postoperatorii, mortalitatea, timpul de spitalizare şi numărul de reinternări.

Rezultate: 18 studii au fost incluse. Majoritatea includ pacienți de peste 70 de ani. Vârstnicii au dezvoltat mai puține complicații şi au necesitat mai puține zile de spitalizare în grupul pacienților ERAS, comparat cu tratamentul convețional. Pacienții cu chirurgie de urgență au dezvoltat mai puține complicații după protocolul ERAS comparat cu grupul convențional. Timpul de 
spitalizare a fost redus în 2 din cele 3 studii pentru chirurgie de urgență.

Concluzii: ERAS poate fi aplicat la vârstnici şi în chirurgia de urgență, cu semnificativă reducere a complicațiilor, spitalizării şi reinternărilor. Evidența stiițifică sugerează ca ERAS este fesabil şi benefic în gestiunea cazurilor de chirurgie geriatrică de urgență.

Cuvinte cheie: chirugie geriatrică, chirurgie de urgență, ERAS

\begin{abstract}
Background: Geriatric surgery is rising and projected to continue at a greater rate. There is already concern about the poor outcomes for the emergency surgery in elderly. How to manage the available resources to improve outcomes in this group of patients is an important object of debate.

Objectives: We aimed to determine the feasibility and safety of applying ERAS pathways to emergency elderly surgical patients.

Method: Two searches were undertaken for ERAS protocols in elderly patients and emergency surgery, in order to gather evidence in relation to ERAS in geriatric emergency patients.

Primary outcomes were postoperative complications, mortality, hospital length of stay and readmission rates.

Results: Eighteen studies were included. The majority of patients were older than 70. Elderly patients had fewer postoperative complications and a reduced hospitalization with ERAS compared to conventional care. Emergency surgical patients also had fewer postoperative complications with ERAS compared to conventional care. Hospital stay was reduced in 2 out of 3 studies for emergency surgery.

Conclusions: ERAS can be safely applied to elderly and emergency patients with a reduction in postoperative complications, hospitalization and readmission rates. There is evidence to suggest that ERAS is feasible and beneficial for geriatric emergency patients.
\end{abstract}

Key words: ERAS, elderly, emergency surgery

\section{Introduction}

The ageing of the population is a multi-factorial, irreversible and global process (1). Over the last three decades the proportion of elderly in Western Europe has increased from $15.5 \%$ to $21.8 \%$ and will reach 30.6\% by 2060 (2). The Annual Ageing Report of the European Commission (2012) predicts than in the next 30 years the number of people 65+ will reach 152 million within the European Union, twice the current number and the number of $80+$ will be tripled.

9 gency surgery (ES). Case complexity, the increased surgical risk and higher mortality rates make emergency surgery in geriatric patients one of the most current topics in general surgery (3); therefore how to manage the available resources to improve outcomes in this group of patients is an important object of debate (4).

Enhanced Recovery after Surgery (ERAS) programmes are evidenced-based protocols designed to standardize and optimize perioperative care in order to reduce surgical trauma, perioperative physiological stress and organ dysfunction (metabolic, endocrine and inflammatory response as well as reduce protein catabolism) related to elective procedures (5). Although published initially for colorectal surgery in 2005, they are now well established for many other surgical conditions. (http:// www.erassociety.org) 


\section{Rationale}

There is already substantial evidence in the literature demonstrating the effectiveness of adopting ERAS based protocols in elective surgery (6-10), resulting in a change in clinical practice and recommendations to use them in ES have already been made by Royal College of Surgeons, UK (11).

Intuitively, ERAS should benefit elderly ES patients due to its design to reduce surgical stress and return functional status more efficiently.

\section{Objectives}

The objective of this review was to evaluate the current evidence as to the applicability, safety and effectiveness of enhanced recovery pathways with geriatric general emergency surgery patients (GES).

\section{Methods}

\section{Protocol and Registration}

The review has been registered in PROSPERO (International prospective register of systematic reviews, (http://www.crd.york.ac.uk/PROSPERO /searchadvanced.php) with the Registration number: CRD42016049271 and was reported in accordance with PRISMA statements (http:// prisma-statement.org).

\section{Eligibility Criteria and Search}

No published studies evaluating enhanced recovery pathways after emergency surgery on elderly were found eligible for selection. With the intention of identifying and extrapolating evidence in relation to ERAS in GES, the search was then divided into two distinct branches; the first was for ERAS in Elderly patients and the second for ERAS in Emergency surgery.

Each search was restricted to the last 10 years. No language restrictions were applied.

The following search strings were used for PubMed and adapted for Cochrane:

i. ERAS (All Fields). AND ("aged" (MeSH
Terms). OR "aged" (All Fields). OR "elderly" (All Fields).)) AND ("2006/01/01" (PDat).: "2016/10 /15"(PDat). AND "humans" (MeSH Terms).)

ii. (enhanced(All Fields). AND recovery (All Fields). AND ("emergencies" (MeSH Terms). OR "emergencies" (All Fields). OR "emergency" (All Fields).) AND ("surgery" (Subheading). OR "surgery" (All Fields). OR "surgical procedures, operative" (MeSH Terms). OR ("surgical" (All Fields). AND "procedures" (All Fields). AND "operative" (All Fields).) OR "operative surgical procedures" (All Fields). OR "surgery" (All Fields). OR "general surgery" (MeSH Terms). OR ("general"(All Fields). AND "surgery" (All Fields).) OR "general surgery" (All Fields).)) AND ("2006/01/01" (PDat): "2016/10/15" (PDat). AND "humans" (MeSH Terms).)

\section{Study Selection}

Titles and abstracts were scrutinized; duplicates and citations removed and full text articles of studies matching search criteria were included. Papers focused on non-abdominal surgery were excluded.

Search i) - Studies which did not provide separate baseline and outcome data specifically in relation to the elderly patient group $(65+$, or $70+$, or $75+$, or $80+$, depending on the study focus) were excluded.

Search ii) - No further specific exclusion criteria were set.

References of relevant studies were then reviewed for possible additional papers.

ERAS guidelines recommend a total of 20 elements (divided into preoperative, intra operative and postoperative), however not all of these are thought feasible for emergency surgery patients and therefore no restriction was placed on the number of elements applied as part of the protocol in each trial/study (12).

The search was independently performed by two reviewers (MP, LP) and disputes were resolved by discussion or the judgement of a third reviewer (IMC) as to which papers should be included, if required.

Fig. 1 gives a summary of the article selection process.

The search conducted with regard to ERAS 


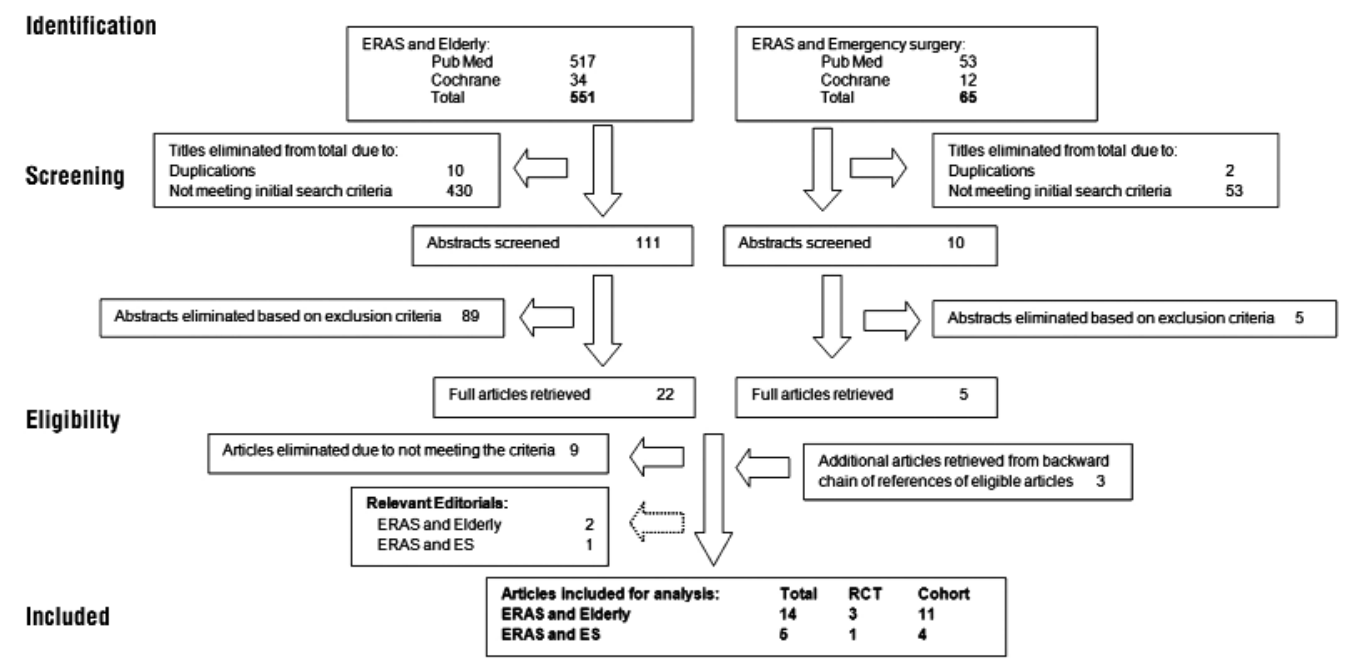

Figure 1. Flow Chart

and Elderly yielded 541 titles and that of ERAS and Emergency Surgery 63, after removal of duplicates. Fourteen papers were judged to be eligible (3 RCTs and 11 cohort studies) in relation to ERAS AND Elderly and 5 for ERAS AND Emergency (4 cohort studies and 1 RCT), Verheijen et al (13). providing separate results for both ERAS and ES and ERAS and Elderly.

Three relevant editorials (14-16) were also found during the search. Although these could not be used within the main body of the review due to not fulfilling all our selection criteria, they were included as part of the discussion as offering expert opinion (level 4 of evidence).

\section{Quality and Risk of Bias Assessment}

The two reviewers independently assessed the methodological quality and risk of bias of the papers selected using levels of evidence according to SIGN (http://www.sign.ac.uk/ methodology/checklists.html) and these are given in Table 1. Fourteen of the eighteen studies in total were rated as acceptable/good quality, 2 as high and 2 as poor quality.

\section{Data Collection}

Data extracted for analysis consisted of patient age, type of surgery performed, ERAS elements implemented, surgical outcomes in terms of overall postoperative complications, mortality, length of stay (LOS) and readmission rates.

\section{Results}

\section{Study Characteristics}

Baseline characteristics from each study are shown in Table 2. The impact of ERAS on a total number of 1214 elderly patients from 14 studies and 311 emergency patients from 5 studies was assessed.

\section{Outcomes}

The outcomes in relation to post operative LOS, complication, readmission and mortality rates reported for each study are summarized in Table 3 and were based on 30 day follow up in the majority of studies.

\section{Analysis of Findings}

Studies comparing ERAS to conventional care, in elderly patients

Four studies compared ERAS to Conventional care (CC) in elderly patients, 3 of which were RCTs in colorectal surgery and 1 Cohort study in pancreaticoduodenectomy (PD). In the 3 RCTs, post operative complication rates were 
Table 1. Quality and risk of bias assessment (SIGN)

\begin{tabular}{|c|c|c|c|c|}
\hline & Study & Type & Overall assessment of the study & Level of evidence \\
\hline \multicolumn{5}{|l|}{ ERAS on Elderly } \\
\hline & Compagna et al. [17] & RCT & Low quality & $1-$ \\
\hline & Jia et al. [18] & $\mathrm{RCT}$ & Acceptable & $1+$ \\
\hline & Wang et al. [19] & RCT & Acceptable & $1+$ \\
\hline & Partelli et al. [20] & Cohort & Acceptable & $2+$ \\
\hline & Kisialueski et al. [21] & Cohort & Acceptable & $2+$ \\
\hline & Baek et al. [22] & Cohort & Acceptable & $2+$ \\
\hline & Coolsen et al. [23] & Cohort & High quality & $2++$ \\
\hline & Khan et al. [24] & Cohort & Acceptable & $2+$ \\
\hline & Pawa et al. [25] & Cohort & Acceptable & $2+$ \\
\hline & Pedziwiatr et al. [26] & Cohort & Acceptable & $2+$ \\
\hline & Rumstadt et al. [27] & Cohort & Acceptable & $2+$ \\
\hline & Walter et al. [28] & Cohort & Acceptable & $2+$ \\
\hline & Gonzalez-Ayora et al. [29] & Cohort & Acceptable & $2+$ \\
\hline \multirow[t]{5}{*}{ ERAS in Emergency } & Gonenc et al. [30] & RCT & Low quality & $1-$ \\
\hline & Lohsiriwat et al. [31] & Cohort & High quality & $2++$ \\
\hline & Wisely et al. [32] & Cohort & Acceptable & $2+$ \\
\hline & Roulin et al. [33] & Cohort & Acceptable & $2+$ \\
\hline & Verheijen et al. [13] & Cohort & Acceptable & $2+$ \\
\hline
\end{tabular}

Table 2. Baseline characteristics of selected studies

\begin{tabular}{|c|c|c|c|c|c|c|}
\hline & Study & Year & No. of patients & Age (years) & Pathology & Comparison \\
\hline \multirow[t]{14}{*}{ ERAS and Elderly } & Compagna et al. & 2014 & $40(36)$ & $>70$ & Colorectal & $\begin{array}{l}\text { ERAS (CC) } \\
\text { all elderly }\end{array}$ \\
\hline & Jia et al. & 2013 & $117(116)$ & $>70$ & Colorectal & \\
\hline & Wang et al. & 2011 & $40(38)$ & $>65$ & Colorectal & \\
\hline & Partelli et al. & 2015 & $22(66)$ & $>75$ & PD & \\
\hline & Kisialeuski et al. & 2015 & $49(43)$ & $>65(<65)$ & Colorectal & $\begin{array}{l}\text { Older (Younger) } \\
\text { all ERAS }\end{array}$ \\
\hline & Baek et al. & 2012 & $77(226)$ & $>70(<70)$ & Colorectal & \\
\hline & Coolsen et al. & 2014 & $55(55)$ & $>70(<65)$ & PD & \\
\hline & Khan et al. & 2016 & 106 (199) & $>75(<75)$ & Colorectal & \\
\hline & Pawa et al. & 2011 & $130(558)$ & $>80(<80)$ & Colorectal & \\
\hline & Pedziwiatr et al. & 2016 & $34(43)$ & $>80(<65)$ & Colorectal & \\
\hline & Rumstadt et al. & 2009 & $207(535)$ & $>79(<79)$ & Colorectal & \\
\hline & Verheijen et al. & 2011 & $81(267)$ & $>80(<80)$ & Colorectal & \\
\hline & Walter et al. & 2010 & $68(332)$ & $>80(<80)$ & Colorectal & \\
\hline & Gonzalez-A. et al. & 2016 & $188^{\#}$ & $>70$ & Colorectal & None \\
\hline \multirow[t]{5}{*}{ ERAS and Emergency } & Gonenc et al. & 2014 & $21(26)$ & $\begin{array}{c}18-66 \\
(35 \pm 13.2)\end{array}$ & $\begin{array}{l}\text { Perforated } \\
\text { ulcer }\end{array}$ & $\begin{array}{c}\text { ERAS (CC) } \\
\text { all emergency }\end{array}$ \\
\hline & Lohsiriwat et al. & 2014 & $20(40)$ & $57.6 \pm 13.2$ & Colorectal & \\
\hline & Wisely et al. & 2014 & $201(169)$ & $\begin{array}{c}18-95 \\
(68)\end{array}$ & $\begin{array}{l}\text { Abdominal } \\
\text { surgery }\end{array}$ & \\
\hline & Roulin et al. & 2014 & $28(63)$ & $\begin{array}{c}18+ \\
(64 \pm 19.5)\end{array}$ & Colorectal & $\begin{array}{l}\text { Emergency } \\
\text { (Elective) } \\
\text { all ERAS }\end{array}$ \\
\hline & Verheijen et al. & 2011 & $41(307)$ & $>18$ & Colorectal & \\
\hline
\end{tabular}

"Compliance and outcomes of a multicenter study on elderly, not having a comparison group.

PD - Pancreaticoduodenectomy, CC - Conventional care, ES - Emergency Surgery 
Table 3. Outcomes reported by study

\begin{tabular}{|c|c|c|c|c|c|}
\hline & $\begin{array}{l}\text { Study } \\
\text { Name }\end{array}$ & $\begin{array}{l}\text { Overall postoperative complications (\%) } \\
\text { Intervention (Comparison) }\end{array}$ & $\begin{array}{c}\text { Mortality } \\
(\%)\end{array}$ & $\begin{array}{l}\text { Length of Hospital stay (days) } \\
\text { Intervention (Comparison) }\end{array}$ & $\begin{array}{c}\text { Readmission rate } \\
(\%)\end{array}$ \\
\hline \multirow[t]{15}{*}{ ERAS and Elderly } & Compagna et al. & $5(18)$ & $3.9 \%$ overall & $6(9.5)$ & Not reported \\
\hline & & $P$ not given & & $P$ not given & \\
\hline & Jia et al. & $\begin{array}{l}27.4(58.6) \\
P<0.05 \text { for cardio-pulmonary and urinary }\end{array}$ & Not reported & $\begin{array}{c}9 \pm 1.75(13 \pm 1.3) \\
P<0.001\end{array}$ & Not reported \\
\hline & Wang et al. & $\begin{array}{c}5(21) \\
P=0.045\end{array}$ & $3.8 \%$ overall & $\begin{array}{c}5.5(7) \\
P<0.001\end{array}$ & Not reported \\
\hline & Partelli et al. & $\begin{array}{l}73(56) \\
P>0.05\end{array}$ & Not reported & $\begin{array}{l}14(11) \\
P>0.05\end{array}$ & $\begin{array}{l}13.6(17) \\
P>0.05\end{array}$ \\
\hline & Kisialeuski et al. & $\begin{array}{l}36.7(34.5) \\
P>0.05\end{array}$ & Not reported & $\begin{array}{l}5.5(4.5) \\
P=0.10\end{array}$ & $\begin{array}{c}6.1(2.3) \\
\text { P not given }\end{array}$ \\
\hline & Baek et al. & $\begin{array}{l}26(31,9) \\
P=0.33\end{array}$ & $0(0)$ & $\begin{array}{c}8(9) \\
P=0.21\end{array}$ & $\begin{array}{c}11.7(4) \\
P=0.013\end{array}$ \\
\hline & Coolsen et al. & $\begin{array}{c}63,5(56,3) \\
P=0.43\end{array}$ & $\begin{array}{l}10.9(5.5) \\
P=0.489\end{array}$ & $\begin{array}{c}14(14) \\
P=0.186\end{array}$ & $\begin{array}{c}12.7(18.1) \\
P=0.44\end{array}$ \\
\hline & Khan et al. & $\begin{array}{l}40,6(47.7) \\
P=0.065\end{array}$ & $\begin{array}{l}0(1.5) \\
P=0.2\end{array}$ & $\begin{array}{c}7(5) \\
P=0.002\end{array}$ & $\begin{array}{c}7(10) \\
P=0.47\end{array}$ \\
\hline & Pawa et al. & $\begin{array}{c}26.2 \text { (9.3) general / } 8.4 \text { (9.6) local } \\
P<0.0001 / P 0.742\end{array}$ & $\begin{array}{l}16.2(2.5) \\
P<0.0001\end{array}$ & $\begin{array}{c}8(6) \\
P=0.36\end{array}$ & $\begin{array}{l}6.2(9.1) \\
P=0.38\end{array}$ \\
\hline & Pedziwiatr et al. & $\begin{array}{c}23.5(37.2) \\
P=0.19\end{array}$ & Not reported & $5.4 \pm 5(7 \pm 7.4)$ & $2.9(2.4)$ \\
\hline & Rumstadt et al. & $\begin{array}{l}38.4(22.9) \\
P<0.001\end{array}$ & $\begin{array}{c}0.9(1.1) \\
\text { P not significant }\end{array}$ & $\begin{array}{c}6(5)^{*} \\
\text { P not significant }\end{array}$ & $\begin{array}{l}2.4(4.6) \\
P<0.05\end{array}$ \\
\hline & Verheijen et al. & $\begin{array}{c}2 \text { (6) anastomotic leaks } \\
\text { P not given }\end{array}$ & $3 \%$ overall & $\begin{array}{c}10(7) \\
\text { P not given }\end{array}$ & $\begin{array}{c}5(11) \\
P \text { not given }\end{array}$ \\
\hline & Walter et al. & $\begin{array}{c}38 \text { (39) - minor } / 7(10) \text { - major } \\
\text { P not significant }\end{array}$ & $\begin{array}{c}4(2) \\
\text { P not significant }\end{array}$ & $\begin{array}{c}7(6) \\
P<0.001\end{array}$ & $\begin{array}{c}4(9) \\
\text { P not significant }\end{array}$ \\
\hline & Gonzalez-A. et al. & $P=0.3$ for grades I-IV Clavien-Dindo & $\begin{array}{c}1.6 \\
\text { P not relevant }\end{array}$ & $\begin{array}{c}6 \\
\text { P not relevant }\end{array}$ & $\begin{array}{c}6.4 \\
\text { P not relevant }\end{array}$ \\
\hline \multirow[t]{5}{*}{ ERAS and Emergency } & Gonenc et al. & $\begin{array}{c}23.8(26.9) \\
P=0.8\end{array}$ & $\begin{array}{c}0(3.8) \\
P=0.36\end{array}$ & $\begin{array}{c}3.8 \pm 1.9(6.9 \pm 2.2) \\
P=0.0001\end{array}$ & $\begin{array}{l}19(7.6) \\
P=0.47\end{array}$ \\
\hline & Lohsiriwat et al. & $\begin{array}{c}25(48) \\
P=0.094\end{array}$ & $0(0)$ & $\begin{array}{l}5.5(7.5) \\
P=0.009\end{array}$ & $0(0)$ \\
\hline & Wisely et al. & $\begin{array}{c}79 \text { (83) - minor / } 31 \% \text { overall - major } \\
\text { less in ERAS group: } P=0.002\end{array}$ & $10(10)$ & $8(8)$ & $\begin{array}{c}10(8) \\
P=0.88\end{array}$ \\
\hline & Roulin et al. & $\begin{array}{l}64(51) \\
P=0.26\end{array}$ & Not reported & $\begin{array}{c}8(5) \\
P=0.006\end{array}$ & $\begin{array}{c}3.57(1.58) \\
P=0.52\end{array}$ \\
\hline & Verheijen et al. & $\begin{array}{c}4 \text { (5) - anastomotic leaks } \\
\text { P not given }\end{array}$ & $3 \%$ overall & $14(7)$ & $10(10)$ \\
\hline
\end{tabular}

*Fit for discharge days. Actual discharge time: 11 (8) due to non-medical related reasons. *P value given for compliance with ERAS elements in elderly

reduced considerably from $18 \%$ to $5 \%$ (17), $58.6 \%$ to $27.4 \%$ (18) and $21 \%$ to $5 \%$ (18) and more notably when laparoscopy was used for all surgeries $(17,19)$.

LOS was reduced by 1.5 to 3.5 and 4 days (17-19).

The cohort study (20) found that outcomes did not improve with the application of ERAS after PD.

Sufficient data was not available to compare readmission or mortality rates.
Studies comparing older to younger patients, in ERAS

Nine studies compared older to younger patient groups receiving ERAS, taking as a reference ages between 65 and 80 . Eight of the studies were in colorectal pathology and 1 in PD (23).

Complication rates ranged from 22.9 to $63 \%$, the highest being in PD, without statistical significance between younger and older patient 
post operative complication rates. Only Pawa et al (25) and Rumstadt et al (27) reported a statistically significant difference in favour of younger over older (80+ and 79+) patients, in general and surgical post operative complications retrospectively. Five of the studies (13,22, 24,26,28). found lower overall complication rates in the older patient group, 3 of these being in $80+$ patients $(13,26,28)$.

Mortality rates varied greatly across the 6 studies which reported on them $(22-25,27,28)$. In the 4 studies where mortality rates were low, there was little difference between age groups $(22,24,27,28)$.

Difference in LOS was between 1 and 2 days longer in general for the older patient group (with the exception of Verheijen). Two studies $(24,28)$ found this to be statistically significant compared to younger patient LOS, however Khan (24) found that LOS in the older patient group was reduced by 1 day when laparoscopy was combined with ERAS.

Six of the nine studies reported lower readmission rates for the older group (13,23-25, $27,28)$, but this was only a statistically significant lower rate in one study (27).

The outcomes reported from the multicentre study undertaken by Gonzalez-A et al (27) had similar postoperative complication rates and LOS to the only other multi-centre study (27).

\section{Studies comparing ERAS to conventional care, in emergency surgery}

In the $1 \mathrm{RCT}$ and 2 cohort studies post operative complication rates were reduced in patients receiving ERAS, with a statistically significant reduction in major complications in one study (32).

LOS was similarly reduced in 2 studies $(30,31)$ by 2-3 days, having statistical significance and mortality rates did not increase or were improved upon (0 vs 3.8\%). Readmission rates were notably poorer in comparison to $\mathrm{CC}$ in the RCT (30).

\section{Studies comparing emergency to elective surgery, in ERAS}

Two studies $(13,33)$. undertook to compare emergency with elective post operative outcomes for colorectal surgery within an ERAS pathway. Although results were poorer for ES patients the only statistically significant difference was in LOS.

\section{ERAS elements applied}

Current ERAS Guidelines were used as the reference point to measure the number of elements applied per study as part of an enhanced recovery protocol. These ranged from 9 to 19 across all the elderly patient studies, with a range of 13 to 17 in those that compared older to younger patients and 13 to 19 in ES, excepting Gonenc et al (30) where it was not clear.

\section{Discussion}

The aim of this systematic review was to evaluate the feasibility of ERAS in geriatric emergency surgery. It is the first of its kind with this focus. Several well documented systematic reviews have been undertaken with regard to the feasibility of ERAS, but less so for ERAS and elderly (34). and none in relation to emergency surgery.

Despite recommendations for the use of ERAS in ES $(11,35)$, there are very few published studies available. We found only 4 studies $(13,23,25,27)$ which included geriatric ES patients in their evaluation of ERAS in elderly which had clearly defined elderly parameters; however GES was not the main focus of these studies.

Two of the 5 studies $(32,33)$ that we found, focusing on ERAS and ES, included elderly patients $(64+)$ as a mean/median age and not as a specific group. As a result, this review has attempted to assess feasibility of Enhanced recovery after geriatric emergency surgery by combining results from studies looking at either elderly and ERAS or ES and ERAS and therefore places some limitations on our recommendations.

In our favour, the quality of the studies was mainly acceptable (SIGN: well conducted cohort studies with a low risk of confounding, bias, or chance and a moderate probability 
that the relationship is causal) and adds weight to the findings.

The evidence for ERAS in elderly patients is good. Although based predominantly on colorectal surgery, 2 studies which evaluated PD with ERAS were included. The overall results show that ERAS is safe, feasible and applicable, with improved outcomes when compared to CC and (in 7 out of 9 studies) no statistically significant differences in post operative complication or readmission rates when compared to younger patients.

LOS was generally longer (with the exception of Pedziwiatr et al (26) but has been partially attributed to non surgical/medical issues $(20,22,25,27)$. Indeed LOS has been questioned as a meaningful outcome to measure in relation to elderly patients. However prolonger hospital stay has been associated with negative factors such as sleep disruption and medication errors (15) and ERAS was seen to reduce post operative hospitalization for both elderly and ES patients in comparison to conventional care.

A systematic review focusing on elderly colorectal patients and enhanced recovery protocols conducted by Bagnall et al. (34) had similar findings. However in this systematic review studies prior to the publication of ERAS consensus guidelines were included and the mean age was used to meet the criterion for elderly.

Although there is diversity in defining elderly (chronological age, geriatric assessment and frailty scales), the studies selected demonstrate a range of ages and co-morbidities in the patients evaluated and can be seen to be representative of the wider aged population. Furthermore, the data is strictly in relation to $65+$ with clearly identifiable outcomes for $70+$ and $80+$ sub groups which conclude that older elderly patients benefit as much if not more than younger ones from ERAS, but have different needs in relation to discharge.

The lower number of trials and studies focusing on ERAS in ES clearly indicates that this is still a new area to explore (16). The studies we found were less homogeneous in focus, included all age groups and different pathologies. Generally, complication rates and LOS were reduced with ERAS. The 3 studies with older patients included had higher LOS than the other 2 studies, which may be attributed to patient age, but is not specified.

Overall, 4 RCTs were included in our review, two of them with a high risk of bias, thus providing weaker level 1 evidence (1-). Although this could be a limitation of our paper, low quality RCTs are still awarded a high ranking value in comparison to cohort studies, but do not contribute to the grade of recommendation. (Appendix 1) All of the RCTs compared ERAS to $\mathrm{CC}$ and all had lower complication rates than the majority of cohort studies. However LOS did not greatly differ, with the exception of Gonenc et al (30), who had the lowest post operative LOS despite being in ES patients. This trial had the youngest mean age and many exclusion criteria, which could account for these results.

The two studies which evaluated ERAS in PD patients had similar results to each other. One study (23) demonstrated elderly patients benefitted from ERAS; the other study (20) concluded ERAS was still safe to apply to this patient group and demonstrated reduced readmission rates. These could be viewed as standalone studies since they had very different pathologies to the others reviewed. Nonetheless, their contribution is valuable in demonstrating the impact of ERAS. There was no validity in comparing the outcomes from these studies with those focused on colorectal surgery, since PD is a challenging operation with a high rate of complications and a measurable mortality risk even in expert hands (36).

Indeed mortality rates were difficult to evaluate generally as they were less frequently reported, with only $50 \%$ of the studies providing comparable results. With the exception of the PD study (23), only Pawa et al (25) reported significantly higher rates for the elderly group due to cardio respiratory complications, possibly due to the premorbid state of the patients. It has been acknowledged that patients over the age of 85 were three times more likely to develop postoperative respiratory complications than those 
Appendix 1. SIGN Levels of Evidence and Grades of Recommendation

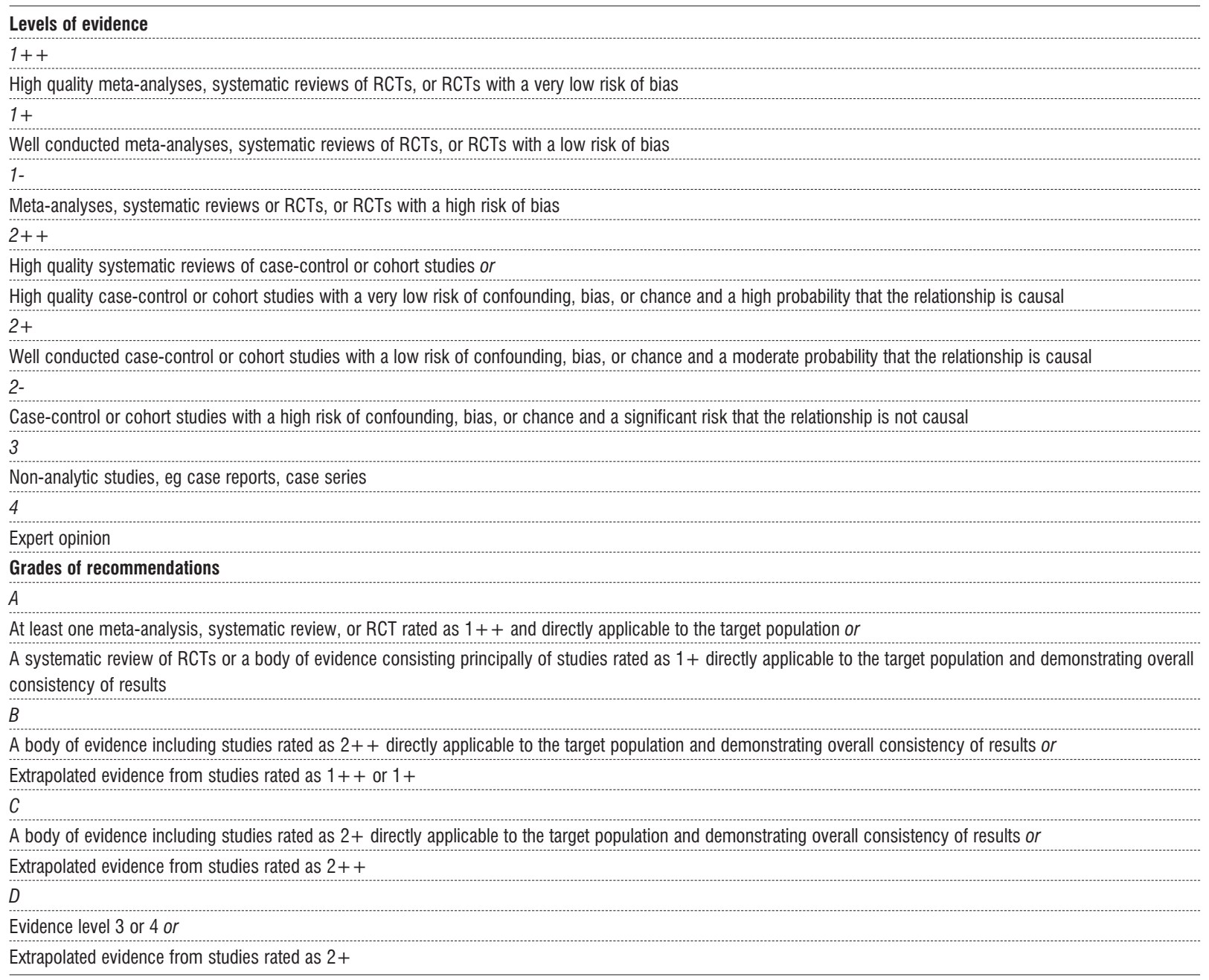

http://www.sign.ac.uk/guidelines/fulltext/50/annexoldb.html

under 65 years of age (37) and in the majority of the studies that we reviewed, where reported, cardio respiratory complications were significantly higher in older compared to younger patients. ERAS was found to reduce this in the studies which compared it to CC $(18,19)$; and Walter et al (28) found that higher ASA and malignancy in older compared to younger patients did not affect outcomes significantly. Therefore, although comorbidity is an important factor to consider when dealing with elderly surgical patients, it should not be used as a prohibiting one (38).

The issue of mortality is an important one in ES, especially in elderly patients. Quiney et al
(16) identified two studies that had applied a specific care pathway with some similarities to ERAS, for ES patients. Their application had resulted in considerably reduced mortality rates.

The use of laparoscopy with ERAS varied in the studies we selected. Two RCTs $(17,19)$ and 3 cohort studies $(21,22,26)$ applied laparoscopic surgery on all patients and Pawa et al (25) on 96\%. Four other studies $(24,27,29,33)$ used laparoscopy to varying degrees and one study (18), in contrast, applied solely open surgery. Despite this variance, no clear patterns could be seen in the outcomes achieved as to the impact of laparoscopy in ERAS. This is still a 
topic for discussion. The systematic review undertaken by Spanjersberg et al (39) explores this in detail and the impact on elderly needs further investigation.

Although the implementation of ERAS elements was generally high, we did not investigate the possible correlation between the number of elements applied and outcomes achieved. What is of note is that high application was demonstrated to be possible in ES and with older patients and that studies with fewer elements applied did not achieve poorer results. In fact, poorest application was in 3 out of the 4 RCTs where the lowest complication rates were recorded.

Two key issues affecting outcomes are study interpretation of individual ERAS elements and patient ability to comply with targets. Interpretation varied in preoperative fasting ranging from 6-8 hours before surgery, with or without carbohydrate loading; post operative early oral feeding ranged from administering solid diet on the first to the third post operative day, and early post operative mobilization from the evening after surgery to the following day.

In ES preoperative ERAS is arguably more difficult to adhere to, however in the studies that we reviewed, there was greater application in the intra and post operative elements. The trial by Gonenc et al (30) stated that 3 key elements produced better outcomes in their intervention group: non NGT usage, early oral feeding and use of NSAIDs. Additionally, work undertaken by the ERAS study group identified 2 key elements which had an independent positive impact on post operative outcomes, perioperative intravenous fluid management and preoperative carbohydrate treatment (40).

More research is still needed in relation to identifying which elements of ERAS have greater impact on both elderly and emergency surgery patients and whether independent impact plays a more significant role than number of elements applied.

Patient compliance was addressed in a number of the studies reviewed (20,23,26,29, $32,33)$ and ranged from 50 to $85 \%$. Emergency surgery patients achieved an average level of compliance in comparison to elective surgical patients, again demonstrating that ERAS in ES is feasible.

\section{Grades of Recommendation (SIGN)}

Summarizing the evidence in the studies analyzed, the following grades of recommendations were given, using SIGN Revised grading system for recommendations in evidence based guidelines (Appendix 1).

B-C for ERAS in Elderly patients, based on: 2 RCTs level 1+, 1 RCT level 1- and 1 Cohort level 2+ comparing ERAS to CC in elderly patients; and 9 Cohort studies level $2+$ and 1 Cohort study level 2++ comparing older to younger patients in ERAS.

$\mathrm{C}$ for ERAS in Emergency patients, basedon: 1 RCT level 1-, 1 Cohort study level 2++ and one Cohort study level 2+, comparing ERAS to CC in Emergencysurgery; and 2 Cohort studies level 2+ comparing Emergency to Elective surgery with ERAS.

C-D for ERAS in GES, based on: extrapolated evidence from 5 Cohort studies level $2+$ and 1 Cohort study level 2++.

\section{Conclusions}

The body of scientific evidence available in relation to ERAS in geriatric patients concludes that it is feasible, safe and effective, with generally better outcomes than conventional care and that age itself is not a prohibiting factor.

ERAS in ES is also concluded to be feasible and safe in the directly applicable studies that we analysed.

Extrapolating data from studies that were either ERAS in elderly which did not exclude emergency cases, or studies on ERAS in Emergency which included elderly patients, we found some evidence to suggest that ERAS was feasible and beneficial for GES patients.

More evidence is clearly required from well designed clinical trials in relation to the impact of ERAS on the heterogeneous emergency geriatric surgical patient. Based on current evidence, we believe that a tailored ERAS 
pathway (which includes frailty assessment, specific discharge strategy and ethical considerations), with a multidisciplinary team approach, would better serve the GES population.

\section{Compliance with Ethical Standards}

\section{Disclosure of Potential Conflicts of Interest}

Mihai Paduraru, Luca Ponchietti, Isidro Martinez Casas, Peter Svenningsen, Jorge Pereira, Aitor Landaluce-Olavarria, Roser Farre Font, Iciar Pascual Miguel, Bakarne Ugarte-Sierra, declare that they have no conflict of interest.

\section{Research Involving Human Participants and/or Animals}

Not applicable.

\section{Informed Consent}

Not applicable.

\section{Acknowledgments}

Melanie Radcliff, BA, for assisting with the English translation.

\section{Authors' contributions}

Mihai Paduraru - Coordinated the group of authors, selection and synthesis of the scientific evidence, wrote and reviewed the article.

Luca Ponchietti - Undertook part of the systematic review and reviewed the article.

Isidro Martinez Casas - Undertook part of the systematic review and reviewed the article. Peter Svenningsen - Undertook part of the systematic review and reviewed the article. Jorge Pereira - Undertook part of the systematic review and reviewed the article.

Aitor Landaluce-Olavarria - Undertook part of the systematic review and reviewed the article. Roser Farre Font - Undertook part of the systematic review and reviewed the article. Iciar Pascual Miguel - Undertook part of the systematic review and reviewed the article. Bakarne Ugarte-Sierra - Undertook part of the systematic review and reviewed the article.

\section{References}

1. Rechel B, Doyle Y, Grundy E, Mckee M. How can health systems respond to population ageing? WHO. 2009.

2. World Population Ageing. United Nations, 2013.

3. Carpinter C, Platts-Mills T. Evolving prehospital, Emergency department and "impatient" Management for Geriatric Emergencies. Clin Geriatr Med. 2014;29(1):1-20.

4. Torrance AD, Powell SL, Griffiths EA. Emergency surgery in the elderly: challenges and solutions. Open Access Emerg Med. 2015; 7:55-68. doi: 10.2147/OAEM.S68324. eCollection 2015.

5. Kehlet $\mathrm{H}$, Wilmore DW. Fast-track surgery. $\mathrm{Br} J$ Surg. 2005;92(1):3-4.

6. Varadhan KK, Neal KR, Dejong $\mathrm{CH}$, Fearon KC, Ljungqvist $\mathrm{O}$, Lobo DN. The enhanced recovery after surgery (ERAS) pathway for patients undergoing major elective open colorectal surgery: a meta-analysis of randomized controlled trials. Clin Nutr. 2010;29(4):434-40. doi: 10.1016/j.clnu.2010.01.004. Epub 2010 Jan 29.

7. Adamina M, Kehlet H, Tomlinson GA, Senagore AJ, Delaney CP. Enhanced recovery pathways optimize health outcomes and resource utilization: a meta-analysis of randomized controlled trials in colo-rectal surgery. Surgery. 2011;149(6):830-40. doi: 10.1016/j.surg. 2010.11.003. Epub 2011 Jan 14.

8. Wind J, Polle SW, Fung Kon Jin PH, Dejong CH, von Meyenfeldt MF, Ubbink DT, et al. Systematic review of enhanced recovery programmes in colonic surgery. Br J Surg. 2006;93(7):800-9.

9. Zhuang $\mathrm{CL}, \mathrm{Ye} X Z$, Zhang XD, Chen BC, Yu Z. Enhanced recovery after surgery programs versus traditional care for colorectal surgery: a meta-analysis of randomized controlled trials. Dis Colon Rectum. 2013;56(5):667-78.

10. Gouvas N, Tan E, Windsor A, Xynos E, Tekkis PP. Fast-track versus standard care in colorectal surgery: a meta-analysis update. Int $\mathrm{J}$ Colorectal Dis. 2009;24(10):1119-31. doi: 10.1007/s00384-0090703-5. Epub 2009 May 5.

11. Royal College of Surgeons UK. Emergency surgery policy briefing. Sept 2014.

12. Gustafsson UO, Scott MJ, Schwenk W, Demartines N, Roulin D, Francis N, et al. Guidelines for perioperative care in elective colonic surgery: Enhanced Recovery After Surgery (ERAS(®)) Society recommendations. World J Surg. 2013;37(2):259-84. doi: 10.1007/s00268-012-1772-0.

13. Verheijen PM, Ven AWH, Davids PHP, Wall BJM, Pronk A. Feasibility of enhanced recovery programme in various patient groups. Int J Colorectal Dis. 2012;27(4):507-11. doi: 10.1007/ s00384-011-1336-z. Epub 2011 Nov 12.

14. Deytrikh A, Tou S, Bergamaschi R. Tailor-made enhanced recovery programme for older patients. Tech Coloproctol. 2015;19(11):6712. doi: 10.1007/s10151-015-1376-4. Epub 2015 Sep 26.

15. Rasmussen LS, Jørgensen CC, Kehlet H. Enhanced recovery programmes for the elderly. Eur J Anaesthesiol. 2016;33(6):391-2. doi: 10.1097/EJA.0000000000000452.

16. Quiney N, Aggarwal G, Scott M, Dickinson M. Survival after emergency general surgery: what can we learn from enhanced recovery programmes? World J Surg. 2016;40(6):1283-7. doi: 10.1007/ s00268-016-3418-0.

17. Compagna R, Aprea G, De Rosa D, Gentile M, Cestaro G, Vigliotti $G$, et al. Fast track for elderly patients: Is it feasible for colorectal surgery? Int J Surg. 2014;12 Suppl 2:S20-S22. doi: 10.1016/ j.ijsu.2014.08.389. Epub 2014 Aug 23.

18. Jia Y, Jin G, Guo S, Gu B, Jin Z, Gao X, et al. Fast-track surgery decreases the incidence of postoperative delirium and other complications in elderly patients with colorectal carcinoma. Langenbecks Arch Surg. 2014;399(1):77-84. doi: 10.1007/s00423013-1151-9. Epub 2013 Dec 13. 
19. Wang Q, Suo J, Jiang J, Wang C, Zhao YQ, Cao X. Effectiveness of fast-track rehabilitation vs conventional care in laparoscopic colo-rectal resection for elderly patients: a randomized trial. Colorectal Dis. 2012;14(8):1009-13. doi: 10.1111/j.1463-1318. 2011.02855.x.

20. Partelli S, Crippa S, Castagnani R, Ruffo G, Marmorale C, Franconi $A M$, et al. Evaluation of an enhanced recovery protocol after pancreatico-duodenectomy in elderly patients. HPB (Oxford). 2016;18(2):153-158. doi: 10.1016/j.hpb.2015.09.009. Epub 2015 Dec 10.

21. Kisialeuski M, Pędziwiatr M, Matłok M, Major P, Migaczewski M, Kołodziej D, et al. Enhanced recovery after colorectal surgery in elderly patients. Wideochir Inne Tech Maloinwazyjne. 2015;10(1): 30-6. doi: 10.5114/wiitm.2015.48697. Epub 2015 Jan 27.

22. Baek SJ, Kim SH, Kim SY, Shin JW, Kwak JM, Kim J. The safety of a "fast-track" program after laparoscopic colorectal surgery is comparable in older patients as in younger patients. Surg Endosc. 2013;27(4):1225-32. doi: 10.1007/s00464-012-2579-7. Epub 2012 Dec 12

23. Coolsen MM, Bakens M, van Dam RM, Olde Damink SW, Dejong CH. Implementing an enhanced recovery program after pancreaticoduodenectomy in elderly patients: is it feasible? World J Surg. 2015; 39(1):251-8. doi: 10.1007/s00268-014-2782-x.

24. Khan MA, Pandey S. Clinical outcomes of the very elderly undergoing enhanced recovery programmes in elective colorectal surgery. Ann R Coll Surg Engl. 2016;98(1):29-33. doi: 10.1308/ rcsann.2015.0036.

25. Pawa N, Cathcart PL, Arulampalam TH, Tutton MG, Motson RW. Enhanced recovery program following colorectal resection in eldery patient. World J Surg. 2012;36(2):415-23. doi: 10.1007/ s00268-011-1328-8.

26. Pedziwiatr M, Pisarska M, Wierdak M, Major P, Rubinkiewicz M, Kisielewski M, et al. The use of the enhanced recovery after surgery (ERAS) protocol in patients undergoing laparoscopic surgery for colorectal cancer - a comparative analysis of patients aged above 80 and below 55. Pol Przegl Chir. 2015;87(11):565-72. doi: 10.1515/pjs-2016-0004.

27. Rumstadt B, Guenther N, Wendling P, Engemann R, Germer CT, Schmid M, et al. Multimodal perioperative rehabilitation for colonic surgery in the elderly. World J Surg. 2009;33(8):1757-63. doi: 10.1007/s00268-009-0018-2.

28. Walter CJ, Watson JT, Pullan RD, Kenefick NJ, Mitchell SJ, DeFriend DJ. Enhanced recovery in major colorectal surgery: Safety and efficacy in an unselected surgical population at a UK district general hospital. The surgeon. 2011:9:259e264

29. Gonzalez-Ayora S, Pastor C, Guadalajara H, Ramirez JM, Royo P,
Redondo $\mathrm{E}$, et al. Enhanced recovery care after colorectal surgery in elderly patients. Compliance and outcomes of a multicenter study from the Spanish working group on ERAS. Int J Colorectal Dis. 2016; 31(9):1625-31. doi: 10.1007/s00384-016-2621-7. Epub 2016 Jul 4

30. Gonenc M, Dural AC, Celik F, Akarsu C, Kocatas A, Kalayci MU, et al. Enhanced postoperative recovery pathways in emergency surgery: a randomised controlled clinical trial. Am J Surg. 2014;207(6):807-14. doi: 10.1016/j.amjsurg. 2013.07.025. Epub 2013 Oct 10.

31. Lohsiriwat V. Enhanced recovery after surgery vs conventional care in emergency colorectal surgery. World J Gastroenterol. 2014; 20(38):13950-5. doi: 10.3748/wjg.v20.i38.13950.

32. Wisely JC and Barclay KL. Effects of an enhanced recovery after surgery programme on emergency surgical patients. ANZ J Surg. 2016;86(11):883-888. doi: 10.1111/ans.13465. Epub 2016 Mar 17.

33. Roulin D, Blanc C, Muradbegovic M, Hahnloser D, Demartines N, Hübner M. Enhanced recovery pathway for urgent colectomy. World J Surg. 2014;38(8):2153-9. doi: 10.1007/s00268-014-2518-y.

34. Bagnall NM, Malietzis G, Kennedy RH, Athanasiou T, Faiz O, Darzi A. A systematic review of enhanced recovery care after colorectal surgery in elderly patients. Colorectal Dis. 2014;16(12):947-56. doi: $10.1111 /$ codi.12718.

35. Khan S, Gatt M, Horgan A, Anderson I, MacFie J. Guidelines for implementation of enhanced recovery protocols. Association of Surgeons of Great Britain and Ireland. 2009.

36. Balzano G, Zerbi A, Capretti G, Rocchetti S, Capitanio V, Di Carlo V. Effect of hospital volume on outcome of pancreaticoduodenectomy in Italy. Br J Surg. 2008;95(3):357-62.

37. Colorectal Cancer Collaborative Group. Surgery for colorectal cancer in elderly patients: a systematic review. Lancet. 2000; 356(9234):968-74.

38. Feroci F, Lenzi E, Baraghini M, Garzi A, Vannucchi A, Cantafio S, et al. Fast-track surgery in real life: how patient factors influence outcomes and compliance with an enhanced recovery clinical pathway after colorectal surgery. Surg Laparosc Endosc Percutan Tech. 2013;23(3): 259-65. doi: 10.1097/SLE.0b013e31828ba16f.

39. Spanjersberg WR, van Sambeeck JD, Bremers A, Rosman C, van Laarhoven CJ. Systematic review and meta-analysis for laparoscopic versus open colon surgery with or without an ERAS programme. Surg Endosc. 2015;29(12):3443-53.

40. Gustafsson UO, Hausel J, Thorell A, Ljungqvist O, Soop M, Nygren J. Enhanced Recovery After Surgery Study Group. Adherence to the enhanced recovery after surgery protocol and outcomes after colorectal cancer surgery. Arch Surg. 2011:146(5):571-7.doi: 10.1001/archsurg.2010.309. Epub 2011 Jan 17. 